\title{
Effects of intravenous L-carnitine on myocardial fatty acid imaging in hemodialysis patients: responders or non-responders to L-carnitine
}

\author{
Masato Nishimura ${ }^{1 *}$, Toshiko Tokoro², Toru Takatani ${ }^{2}$, Nodoka Sato $^{3}$, Masaya Nishida $^{3}$, Tetsuya Hashimoto ${ }^{3}$, \\ Satoru Yamazaki ${ }^{4}$, Hiroyuki Kobayashi ${ }^{3}$ and Toshihiko Ono ${ }^{3}$
}

\begin{abstract}
We investigated whether chronic intravenous administration of L-carnitine could improve myocardial fatty acid imaging in patients on maintenance hemodialysis. We enrolled 72 hemodialysis patients who had impaired myocardial fatty acid imaging and left ventricular dysfunction not based on coronary lesion. L-Carnitine (1,000 mg) was intravenously administered after dialysis for 1 year to 36 participants (Carnitine group), while not in the other 36 participants (Control group). Single-photon emission computed tomography (SPECT) using an iodinated fatty acid analogue, BMIPP, was performed. Uptake on SPECT images was graded in 17 segments on a five-point scale (0, normal; 4, absent) and assessed as BMIPP summed scores. During follow-up, 19 participants were discontinued from the study, and 53 participants (65 \pm 12 years: 27 carnitine, 26 control) were analyzed. The mean BMIPP summed scores 1 year after carnitine administration did not differ from that before in the carnitine group, nor from that in the control group. However, improved SPECT (Changes in BMIPP summed scores <-20\%) was found in 7 (25.9\%) participants in the carnitine, whereas in 2 (7.7\%) in the control group. Multivariate logistic analysis showed the improved SPECT was inversely associated with baseline serum albumin levels (1 g/L: odds ratio, 0.669); the cut-off was $35 \mathrm{~g} / \mathrm{L}$. Chronic intravenous L-carnitine might improve myocardial fatty acid imaging in a selected group of hemodialysis patients with hypoalbuminemia.
\end{abstract}

Keywords: Carnitine, Fatty acid, Heart, Hypoalbuminemia, Imaging, Uremic cardiomyopathy

\section{Background}

Carnitine plays an important role in myocardial fatty acid metabolism by transporting long-chain free fatty acids (FFA) from the cytoplasm to the matrix of myocardial and skeletal muscle mitochondria for $\beta$-oxidation. The effects of L-carnitine on the cardiovascular complications of dialysis patients are still controversial, although supplementation of L-carnitine in dialysis patients has been reported to improve left ventricular (LV) dysfunction and arrhythmia in some studies (Van ES et al.

\footnotetext{
*Correspondence: mnishimura@tea.ocn.ne.jp

${ }^{1}$ Cardiovascular Division, Toujinkai Hospital, 83-1, Iga, Momoyama-cho,

Fushimi-ku, Kyoto 612-8026, Japan

Full list of author information is available at the end of the article
}

1992; Matsumoto et al. 2000; Romagnoli et al. 2002; Suzuki et al. 1982). Sakurabayashi et al. reported that chronic oral administration of L-carnitine to hemodialysis patients did not change myocardial accumulation of ${ }^{123} \mathrm{I}-\beta$-methyliodophenyl pentadecanoic acid (BMIPP), an iodinated analogue of free FFA, or LV dimension or function, but it increased the washout rate of ${ }^{123}$ I-BMIPP (Sakurabayashi et al. 1999). However, no study has been reported regarding the effect of L-carnitine on singlephoton emission computed tomography (SPECT) using ${ }^{123}$ I-BMIPP, of which improvement may contribute to betterment of LV dysfunction or decrease in cardiac death (Nishimura et al. 2006, 2008a, b, 2011, 2014, 2015; Moroi et al. 2013). In the present study, we investigated

\section{Springer}

(c) 2015 Nishimura et al. This article is distributed under the terms of the Creative Commons Attribution 4.0 International License (http://creativecommons.org/licenses/by/4.0/), which permits unrestricted use, distribution, and reproduction in any medium, provided you give appropriate credit to the original author(s) and the source, provide a link to the Creative Commons license, and indicate if changes were made. 
whether chronic intravenous administration of L-carnitine could improve impaired myocardial fatty acid imaging in patients on maintenance hemodialysis with LV dysfunction not based on obstructive coronary artery disease (CAD) or valvular heart diseases.

\section{Methods}

\section{Study population}

Figure 1 shows a participant flow chart, which proceeded at the two dialysis centers associated with the Toujinkai Group: Toujinkai Hospital and Toujinkai Clinic. Eligibility criteria of this study were as follows: (1) Patients on chronic hemodialysis with a history of heart failure needing hospitalization (grade IVof New York Heart Association) except fluid overload from June 1st, 2012 to May 31st, 2013; (2) No significant obstructive CAD identified by angiography within one year of the study (from June 1st, 2012 to May 31st, 2013); (3) LV dysfunction evaluated by echocardiography: mildly or moderately reduced LV systolic function [left ventricular ejection fraction (LVEF) <55\%] and/or LV hypertrophy, which indicates LV remodeling and lowered LV diastolic function; and (4) BMIPP summed scores (SS) $\geqq 4$, which was based on the results of the B-SAFE study (Moroi et al. 2013). Criteria for exclusion from participation were (1) Moderate or worse valvular heart disease; (2) Past history of acute or old myocardial infarction and/or coronary revascularization by percutaneous coronary intervention or coronary artery bypass grafting. Eighty-seven hemodialysis patients in the Toujinkai Group met the eligibility criteria; however, ten patients were excluded based on the exclusion criteria, and five patients refused to participate this study. Consequently, 72 hemodialysis patients were enrolled in this study between June 1st and 30th of 2013 (40 men and 32 women, mean age: $64 \pm 11$ years; mean dialysis duration: $146 \pm 96$ months). Simple randomization was performed by assigning the participants to the carnitine or control group (1:1) in the order of enrollment; the person who was not involved in this study performed this randomized assignment of participants to the two groups. From August 1st, 2013 to July 31st, 2014, L-carnitine (L-Cartin ${ }^{\circledR}$ FF, Otsuka Pharmaceutical Co., Ltd. Tokyo, Japan) was intravenously administered after each dialysis session to 36 participants (Carnitine group), while the other 36 participants were not administered L-carnitine (Control group). The dose of intravenous administration of L-carnitine was uniformly $1,000 \mathrm{mg}$ on each hemodialysis session. The Ethics Committee for Human Research of the Toujinkai Group approved the study protocol, and all participants provided written, informed consent to participate in all procedures associated with the study. The study was performed in accordance with the principles of the Declaration of Helsinki, and registered to the ClinicalTrials. gov (https://www.clinicaltrials.gov/): protocol identifier, NCT02322697.

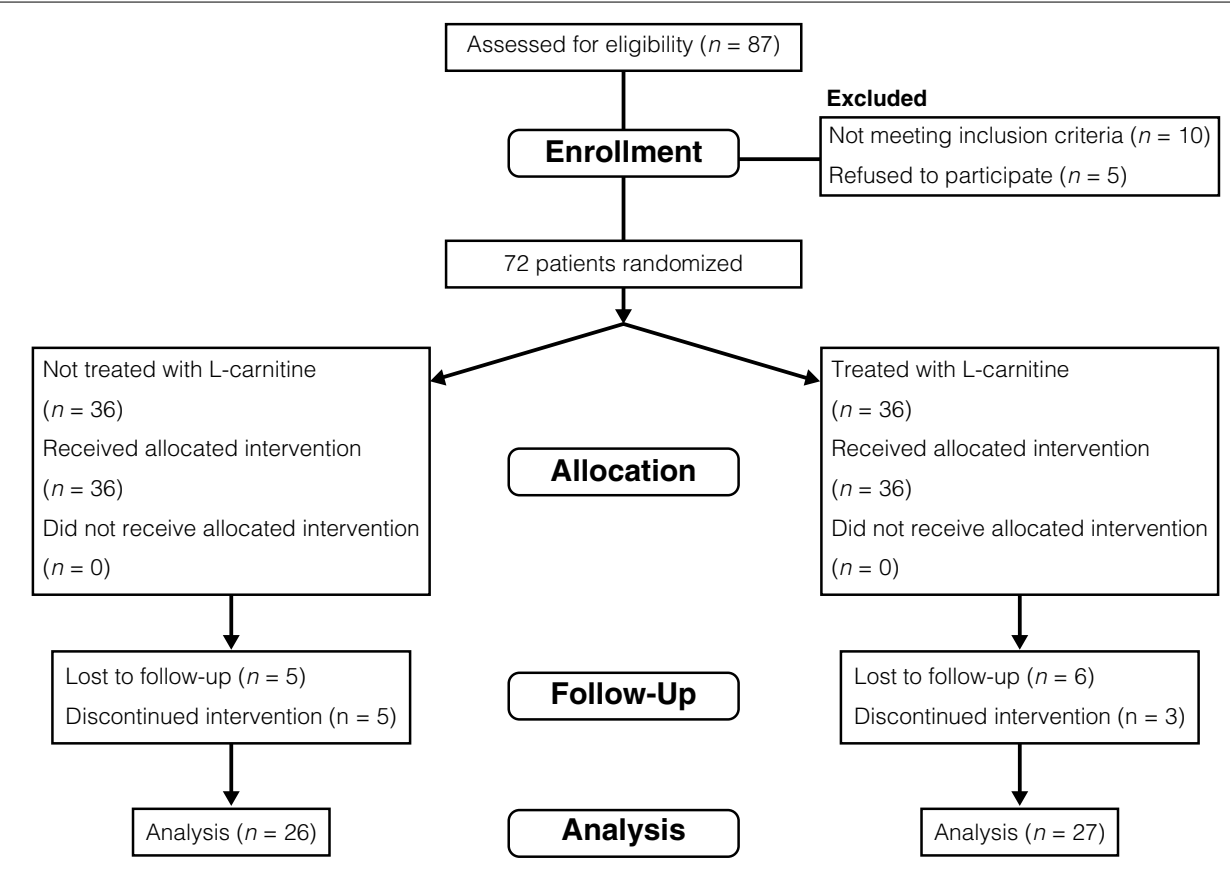

Figure 1 Participant flow chart. 


\section{Coronary angiography (CAG)}

Experienced interventional cardiologists performed quantitative CAG at the Department of Interventional Cardiology of Kyoto Second Red Cross Hospital using a validated automated edge-detection program (CCIP310/W, CATHEX, Tokyo, Japan). Significant coronary artery stenosis was defined as stenosis of $>50 \%$ diameter on CAG images.

\section{Radionuclide imaging}

All participants underwent resting ${ }^{123}$ I-BMIPP SPECT after fasting for over $6 \mathrm{~h}$ on a midweek, non-dialysis day within 1 month before the study and at 1 year after starting the study. Details of the dual BMIPP SPECT procedure are described elsewhere (Nishimura et al. 2006, 2008a, b, 2011). The images were divided into 17 segments for semiquantitative analysis according to the standard myocardial segmentation for tomographic heart imaging established by the American Heart Association. The amount of radioactivity taken up by each segment was visually graded and assigned an uptake score of 0 (normal), 1 (mildly reduced), 2 (moderately reduced), 3 (severely reduced), or 4 (none). The BMIPP SPECT scores for 17 myocardial segments were designated as BMIPP SS. The same experienced technician performed all scintigraphic procedures. All BMIPP SPECT images were interpreted within one week of the SPECT examination by the same two investigators. Both of them interpreted SPECT images at the same time without knowledge of the identity (name), clinical condition (age, gender, blood pressure, presence or absence of diabetes mellitus, cardiothoracic ratio, dialysis duration and cardiac functions evaluated by echocardiography), and laboratory data about the participant. The information about the assignment of participants to carnitine or control group was not given to these two investigators at the interpretation of BMIPP SPECT.

\section{Echocardiography}

The participants underwent two-dimensionally guided echocardiography using a single ultrasonographic recorder (HD11XD, Philips, the Netherlands) on a midweek non-dialysis day within 1 month before the study, 6 months, and 12 months after starting the study. LVEF levels were quantified using the biplanar Simpson's rule, and left ventricular mass was measured as recommended by the American Society of Echocardiography. Mitral early to atrial (E/A) wave velocity ratio was measured as an index of LV diastolic function. Left ventricular mass was normalized to body surface area, and is described herein as left ventricular mass index (LVMI). Criteria for LV hypertrophy were an LVMI exceeding $134 \mathrm{~g} / \mathrm{m}^{2}$ in men or $110 \mathrm{~g} / \mathrm{m}^{2}$ in women (Sahn et al. 1978).

\section{Biochemical and hematological determinations}

On the first hemodialysis session of the week within 30 days before starting the study, blood samples $(10 \mathrm{ml})$ were obtained from patients who had fasted overnight and rested for $10 \mathrm{~min}$. Blood hemoglobin $(\mathrm{Hb})$, plasma B-type natriuretic peptide (BNP) concentration, and serum concentrations of calcium, inorganic phosphorus, albumin, total cholesterol, C-reactive protein (CRP), and intact parathyroid hormone were determined. Plasma BNP concentrations were measured additionally at 6 months and 12 months after starting the study. We used fasting plasma glucose and fasting plasma insulin concentrations to calculate the homeostasis model assessment of insulin resistance (HOMA-IR) as fasting glucose concentration $(\mathrm{mmol} / \mathrm{L}) \times$ fasting insulin concentration $(\mu \mathrm{U} / \mathrm{ml}) / 22.5$. Blood samples were collected on the same day to measure this and other biochemical and hematological parameters. Serum concentrations of total, free, and acyl carnitine were determined within 30 days before the study, and 3, 6, and 12 months after starting the study using enzymatic cycling method (SRL, Inc. Tokyo, Japan) (Takahashi et al. 1994). The same erythropoiesis stimulating agent (ESA) (Epoetin beta pegol, C.E.R.A., Chugai Pharmaceutical Co., Ltd., Tokyo, Japan) was administered to all participants. The ESA resistance index (ERI) was determined as the monthly weight-adjusted dose of ESA $(\mu \mathrm{g} / \mathrm{kg})$ divided by $\mathrm{Hb}$ concentration $(\mathrm{g} / \mathrm{L})$. Changes in ERI before and 1 year after carnitine administration were calculated as follows: (ERI at 1 year after carnitine administration-ERI before carnitine administration)/ ERI before carnitine administration $\times 100(\%)$. We used the dose of ESA and mean blood Hb of the month just before starting this study (July, 2013) for calculation of ERI before carnitine administration and the dose of ESA and mean blood $\mathrm{Hb}$ of the last month of this study (July, 2014) for calculation of ERI after carnitine administration. Decrease in ERI over 50\% was defined as improvement of ERI, whereas increase in ERI over $50 \%$ as aggravation of ERI.

\section{Statistical analysis}

Values are expressed as mean $\pm \mathrm{SD}$. We compared the means of continuous variables using paired or non-paired $t$ tests. Categorical data were analyzed using the $\chi^{2}$ test. Threshold for the serum albumin concentration for changes in BMIPP SS $<-20 \%$ was defined using receiveroperating characteristic (ROC) analysis. Any covariates that tended to be significant in univariate logistic analyses $(P<0.1)$ were assessed by multiple logistic analysis. $P$ values $<0.05$ were considered significant. Individuals without knowledge of the participants' profiles and clinical data performed all statistical analyses. All statistical analyses were performed with SAS software version 8.2. 


\section{Results}

During the follow-up of 72 participants from Aug 1st, 2013 to July 31st, 2014, 11 participants were lost for follow-up, and 8 participants were discontinued from this study (Figure 1). In the carnitine group $(n=36), 5$ participants died ( 2 sudden death, 2 infection, 1 heart failure), one participant changed the dialysis center, and three participants dropped out from the study (one participant had severe diarrhea after administering L-carnitine, and the other two participants had refused subsequent BMIPP SPECT). In the control group $(n=36), 5$ participants died ( 2 sudden death, 2 heart failure, 1 malignancy), and five participants had refused subsequent BMIPP SPECT. Consequently, we analyzed the data of 53 participants $(27$ men and 26 women; mean age, $65 \pm 12$ years; hemodialysis duration, $149 \pm 105$ months: carnitine group, $n=27$; control group, $n=26$ ). Clinical baseline characteristics did not differ between the carnitine and control groups (Table 1).

\section{Circulating carnitine and BNP concentrations and cardiac functions}

Compared with the normal ranges of serum carnitine concentrations in the laboratory used for measurement in this study (total carnitine, $45-91 \mu \mathrm{mol} / \mathrm{L}$; free carnitine, 36-74 $\mu \mathrm{mol} / \mathrm{L}$; acyl carnitine, $16-23 \mu \mathrm{mol} / \mathrm{L}$ ) (Takahashi et al. 1994), mean baseline serum concentration of free carnitine seemed to be lower, and that of acyl carnitine higher in the participants. Mean baseline serum concentration of total carnitine did not differ with that of normal controls (Table 2). Mean serum concentrations of total, free, and acyl carnitine increased at 3 months of intravenous administration of L-carnitine. Mean serum concentrations of total and free carnitine were further increased at 12 months compared with 3 or 6 months of carnitine administration, whereas mean serum concentration of acyl carnitine did not differ among 3, 6, or 12 months of carnitine administration. Mean values of acyl/free carnitine ratio did not differ at 3,6 , or 12 months of carnitine administration compared with before administration, but decreased at 12 months compared with 3 or 6 months (Table 2).

In the control group, mean values of plasma BNP concentration, LVEF, and LVMI did not differ among before carnitine administration, at 6 months, and at 12 months of administration (Table 3). In the carnitine group, mean values of plasma BNP or LVEF did not alter among before, at 6 months, and at 12 months of carnitine administration, but LVMI was increased at 12 months of carnitine administration compared with before carnitine administration. Mean mitral E/A wave velocity ratio did not alter among before, at 6 , and at 12 months in the control or carnitine groups (Table 3 ).
Table 1 Baseline clinical characteristics in the control and cartinine groups

\begin{tabular}{|c|c|c|c|}
\hline & $\begin{array}{l}\text { Control } \\
(n=26)\end{array}$ & $\begin{array}{l}\text { Carnitine } \\
(n=27)\end{array}$ & $P$ \\
\hline Age, y & $64.3 \pm 12.9$ & $64.7 \pm 12.0$ & 0.892 \\
\hline Male gender, $n(\%)$ & $14(53.9)$ & $14(51.9)$ & 0.887 \\
\hline Dialysis duration, months & $141.2 \pm 83.8$ & $149.1 \pm 105.2$ & 0.763 \\
\hline Smoking, $n(\%)$ & $9(34.6)$ & $9(33.3)$ & 0.923 \\
\hline Alcohol, $n(\%)$ & $8(30.8)$ & $8(29.6)$ & 0.930 \\
\hline Diabetes mellitus, $n(\%)$ & $13(50.0)$ & $14(51.9)$ & 0.895 \\
\hline $\begin{array}{l}\text { Systolic blood pressure before } \\
\text { dialysis, } \mathrm{mm} \mathrm{Hg}\end{array}$ & $138.0 \pm 12.1$ & $134.0 \pm 18.8$ & 0.360 \\
\hline $\begin{array}{l}\text { Diastolic blood pressure before } \\
\text { dialysis, } \mathrm{mm} \mathrm{Hg}\end{array}$ & $73.4 \pm 10.6$ & $70.5 \pm 14.7$ & 0.408 \\
\hline Body mass index, $\mathrm{kg} / \mathrm{m}^{2}$ & $21.2 \pm 4.5$ & $22.9 \pm 4.1$ & 0.170 \\
\hline Cardiothoracic ratio, \% & $53.1 \pm 5.8$ & $53.3 \pm 4.9$ & 0.922 \\
\hline $\begin{array}{l}\text { Left ventricular ejection fraction, } \\
\%\end{array}$ & $52.2 \pm 11.9$ & $53.2 \pm 11.9$ & 0.696 \\
\hline Left ventricular mass index, $\mathrm{g} / \mathrm{m}^{2}$ & $126.6 \pm 24.8$ & $126.4 \pm 24.1$ & 0.962 \\
\hline $\begin{array}{l}\text { Mitral early to atrial (E/A) wave } \\
\text { velocity ratio }\end{array}$ & $1.2 \pm 0.6$ & $1.1 \pm 0.6$ & 0.875 \\
\hline Blood hemoglobin, g/L & $106.8 \pm 10.8$ & $106.1 \pm 9.0$ & 0.800 \\
\hline Serum albumin, $g / L$ & $37.8 \pm 2.9$ & $37.9 \pm 3.4$ & 0892 \\
\hline Serum calcium, mmol/L & $2.2 \pm 0.1$ & $2.2 \pm 0.1$ & 0.451 \\
\hline $\begin{array}{l}\text { Serum inorganic phosphorus, } \\
\mathrm{mmol} / \mathrm{L}\end{array}$ & $1.6 \pm 0.4$ & $1.6 \pm 0.3$ & 0.810 \\
\hline Serum total cholesterol, $\mathrm{mmol} / \mathrm{L}$ & $4.1 \pm 0.6$ & $3.9 \pm 1.1$ & 0.515 \\
\hline Serum ferritin, pmol/L & $273.9 \pm 185.8$ & $281.8 \pm 197.7$ & 0.859 \\
\hline $\begin{array}{l}\text { Serum intact parathyroid hor- } \\
\text { mone, ng/L }\end{array}$ & $176.1 \pm 99.3$ & $133.4 \pm 106.0$ & 0.136 \\
\hline Serum C-reactive protein, mg/L & $2.5 \pm 2.2$ & $2.2 \pm 2.6$ & 0.635 \\
\hline $\begin{array}{l}\text { Plasma B-type natriuretic peptide, } \\
\text { ng/L }\end{array}$ & $291.2 \pm 174.6$ & $249.2 \pm 229.1$ & 0.457 \\
\hline $\mathrm{HOMA}-\mathrm{IR}, \mathrm{mmol} / \mathrm{L} \cdot \mu \mathrm{U} / \mathrm{ml}$ & $5.9 \pm 1.9$ & $5.3 \pm 2.3$ & 0.294 \\
\hline BMIPP summed score & $18.2 \pm 6.0$ & $18.9 \pm 11.3$ & 0.794 \\
\hline \multicolumn{4}{|l|}{ Medications } \\
\hline$\alpha_{1}$ blockers, $n(\%)$ & $2(7.7)$ & $3(11.1)$ & 0.677 \\
\hline$\beta$ blockers, $n(\%)$ & $17(65.4)$ & $17(63.0)$ & 0.858 \\
\hline Calcium blockers, $n(\%)$ & $7(26.9)$ & $7(25.9)$ & 0.936 \\
\hline RAS inhibitors, $n(\%)$ & $8(30.8)$ & $9(33.3)$ & 0.845 \\
\hline Nitrates, $n(\%)$ & $3(11.5)$ & $3(11.1)$ & 0.962 \\
\hline Antiplatelet drugs, $n$ (\%) & $16(61.5)$ & $18(66.7)$ & 0.704 \\
\hline Anticoagulation drugs, $n(\%)$ & $3(11.5)$ & $5(18.5)$ & 0.487 \\
\hline Statins, $n(\%)$ & $7(26.9)$ & $7(25.9)$ & 0.936 \\
\hline
\end{tabular}

HOMA-IR the homeostasis model assessment index of insulin resistance, RAS renin-angiotensin system.

\section{Carnitine and myocardial fatty acid imaging}

In the control group, the mean BMIPP SS did not differ between before and 12 months after carnitine administration (18.2 \pm 6.0 versus $18.7 \pm 6.4, n=26)$ (Figure 2a). Since we have reported that decrease in BMIPP SS $<-20 \%$ might result in improving cardiac mortality of 
Table 2 Changes in serum concentrations of carnitine after intravenous administratin of L-carnitine

\begin{tabular}{llllc}
\hline & Before & 3 months & $\mathbf{6}$ months & 12 months \\
\hline $\begin{array}{l}\text { Total } \\
\text { carnitine, }\end{array}$ & $62.4 \pm 59.0$ & $380.8 \pm 96.0^{*}$ & $406.6 \pm 73.3^{*}$ & $441.1 \pm$ \\
$\mu \mathrm{mol} / \mathrm{L}$ \\
$\begin{array}{c}\text { Free } \\
\text { carnitine, }\end{array}$ & $37.6 \pm 38.3$ & $220.9 \pm 52.7^{*}$ & $236.4 \pm 41.5^{*}$ & $264.9 \pm$ \\
$\mu \mathrm{mol} / \mathrm{L}$ \\
$\begin{array}{c}\text { Acyl } \\
\text { carnitine, } \\
\mu \mathrm{mol} / \mathrm{L}\end{array}$ & $24.7 \pm 21.3$ & $159.9 \pm 49.1^{*}$ & $170.2 \pm 43.8^{*}$ & $176.1 \pm 51.5^{*}$ \\
$\begin{array}{c}\text { Acyl/free } \\
\text { carnitine } \\
\text { ratio }\end{array}$ & $0.70 \pm 0.14$ & $0.72 \pm 0.14$ & $0.73 \pm 0.17$ & $0.67 \pm 0.1^{\dagger \rho}$ \\
\hline
\end{tabular}

${ }^{*} P<0.01$ versus before; ${ }^{\dagger} P<0.05$ versus 3 months; ${ }^{+\dagger} P<0.01$ versus 3 months; ${ }^{\int} P<0.05$ versus 6 months; $\iint^{P}<0.01$ versus 6 months.

Table 3 Changes in plasma B-type natriuretic peptide concentrations and left ventricular function in the control and carnitine group

\begin{tabular}{|c|c|c|c|}
\hline & Before & 6 months & 12 months \\
\hline \multicolumn{4}{|l|}{ Control group $(n=26)$} \\
\hline $\begin{array}{l}\text { Plasma B-type natriu- } \\
\text { retic peptide, ng/L }\end{array}$ & $291.2 \pm 174.6$ & $285.6 \pm 165.9$ & $310.1 \pm 168.8$ \\
\hline $\begin{array}{l}\text { Left ventricular ejection } \\
\text { fraction, } \%\end{array}$ & $52.2 \pm 4.8$ & $52.0 \pm 5.7$ & $51.9 \pm 6.0$ \\
\hline $\begin{array}{l}\text { Left ventricular mass } \\
\text { index, } \mathrm{g} / \mathrm{m}^{2}\end{array}$ & $126.4 \pm 24.1$ & $126.3 \pm 25.1$ & $126.5 \pm 23.8$ \\
\hline $\begin{array}{l}\text { Mitral early to atrial (E/A) } \\
\text { wave velocity ratio }\end{array}$ & $1.1 \pm 0.6$ & $1.1 \pm 0.7$ & $1.1 \pm 0.6$ \\
\hline \multicolumn{4}{|l|}{ Carnitine group $(n=27)$} \\
\hline $\begin{array}{l}\text { Plasma B-type natriu- } \\
\text { retic peptide, ng/L }\end{array}$ & $249.2 \pm 229.1$ & $274.2 \pm 213.2$ & $360.2 \pm 440.3$ \\
\hline $\begin{array}{l}\text { Left ventricular ejection } \\
\text { fraction, } \%\end{array}$ & $53.2 \pm 11.9$ & $54.0 \pm 11.7$ & $53.7 \pm 9.5$ \\
\hline $\begin{array}{l}\text { Left ventricular mass } \\
\text { index, } \mathrm{g} / \mathrm{m}^{2}\end{array}$ & $126.6 \pm 24.8$ & $138.0 \pm 39.3$ & $140.9 \pm 34.8^{*}$ \\
\hline $\begin{array}{l}\text { Mitral early to atrial }(E / A) \\
\text { wave velocity ratio }\end{array}$ & $1.2 \pm 0.5$ & $1.1 \pm 0.6$ & $1.1 \pm 0.6$ \\
\hline
\end{tabular}

hemodialysis patients in our recent studies (Nishimura et al. 2014, 2015), we subdivided participants of the carnitine and control groups into the following three subgroups according to the changes in BMIPP SS: improved subgroup, changes in BMIPP SS $<-20 \%$; deteriorated subgroup, changes in BMIPP SS $>20 \%$; unchanged subgroup, changes in BMIPP SS $\pm 20 \%$. In the control group $(n=26), 2(7.7 \%), 4(15.4 \%)$, and $20(76.9 \%)$ participants were allocated to the improved, deteriorated, and unchanged subgroup, respectively. In the carnitine group, the mean BMIPP SS also did not differ between before and 12 months after carnitine administration

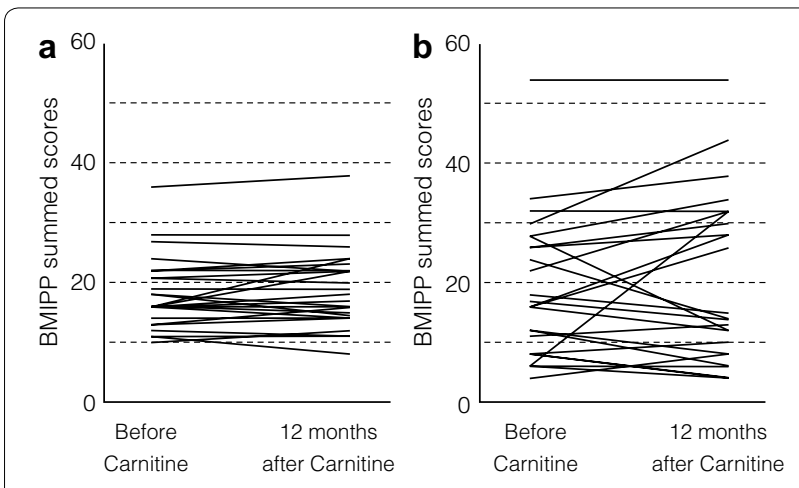

Figure 2 Changes in BMIPP summed scores before and 12 months after carnitine administration. a Control group, $n=26$. b Carnitine group, $n=27$.

(18.9 \pm 11.3 versus $20.7 \pm 13.5, n=27$ ) (Figure $2 b)$. In the carnitine group $(n=27), 7(25.9 \%), 8(29.6 \%)$, and $12(44.5 \%)$ participants were allocated to the improved, deteriorated, and unchanged subgroup, respectively. Figure 3 shows one of the improved cases in the carnitine group. The allocation to improved subgroup was greater $(P=0.025)$ in the carnitine than in the control group, whereas the allocation to deteriorated subgroup did not differ between the two groups $(P=0.2)$.

\section{Differences in baseline clinical or laboratory data and cardiac function by changes in BMIPP SS}

The baseline mean LVEF was lower in the improved subgroup than in the deteriorated subgroup, and the baseline mean values of serum albumin and total cholesterol concentrations were lower in the improved subgroup than in the unchanged subgroup (Table 4). Mean serum baseline concentrations of total, free, or acyl carnitine and acyl/free carnitine ratio did not differ among the three subgroups (Table 4). In addition, mean serum carnitine concentrations and acyl/free carnitine ratio 1 year after L-carnitine administration did not differ among the subgroups (total carnitine: changes in BMIPP SS <-20\%, 464.4 $\pm 156.5 \mu \mathrm{mol} / \mathrm{L}$, changes in BMIPP $\mathrm{SS} \pm 20 \%, 441.3 \pm 85.7 \mu \mathrm{mol} / \mathrm{L}$, changes in BMIPP SS $>20 \%, 420.3 \pm 70.5 \mu \mathrm{mol} / \mathrm{L}$; free carnitine: SS $<-20 \%$, $286.4 \pm 93.6 \mu \mathrm{mol} / \mathrm{L}, \mathrm{SS} \pm 20 \%, 255.8 \pm 45.9 \mu \mathrm{mol} / \mathrm{L}$, SS $>20 \%, 259.9 \pm 39.7 \mu \mathrm{mol} / \mathrm{L}$; acyl carnitine: $\mathrm{SS}<-20 \%$, $178.1 \pm 75.0 \mu \mathrm{mol} / \mathrm{L}, \mathrm{SS} \pm 20 \%, 185.5 \pm 45.3 \mu \mathrm{mol} / \mathrm{L}$, SS $>20 \%, 160.4 \pm 37.1 \mu \mathrm{mol} / \mathrm{L}$; acyl/free carnitine ratio: SS $<-20 \%, 0.62 \pm 0.15$, SS $\pm 20 \%, 0.72 \pm 0.12$, SS $>20 \%$, $0.62 \pm 0.11$ ). Mean changes in LVEF after administration of L-carnitine were better in the improved subgroup $(28.3 \pm 15.9 \%)$ compared with the unchanged $(3.5 \pm 23.7 \%)$ or deteriorated subgroup $(-13.6 \pm 13.1 \%)$ (Figure 4). 

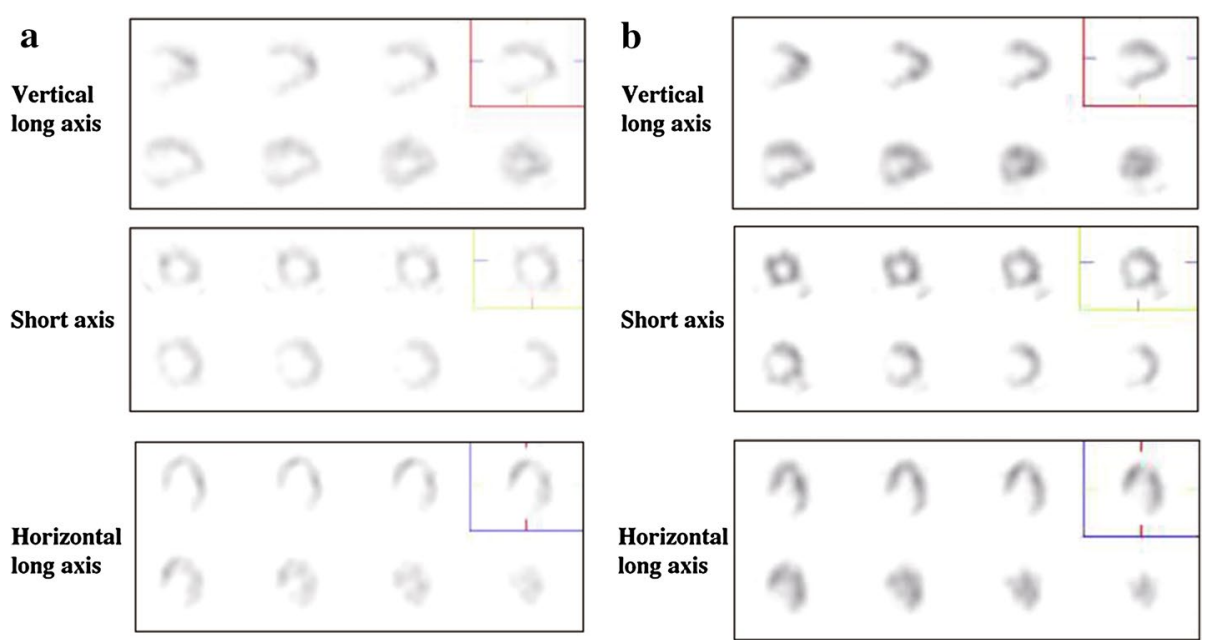

Figure 3 BMIPP SPECT images from a participant who showed improvement after administration of L-carnitine: a 70-year-old non-diabetic woman whose dialysis duration was 22 years. BMIPP summed scores were 28 before administration of L-carnitine (a) and 12 after administration of L-carnitine for one year (b). Left ventricular ejection fraction evaluated by echocardiography also improved, from 43 to $62 \%$ after administration of L-carnitine. Her baseline serum albumin concentration was $34 \mathrm{~g} / \mathrm{L}$.

\section{Factors related with improvement in BMIPP SPECT after carnitine administration}

In an univariate logistic analysis, changes in BMIPP SS $<-20 \%$ (Improved BMIPP SPECT) was significantly associated with baseline serum concentrations of albumin, total cholesterol, and CRP, and tended to be associated with baseline LVEF and serum ferritin concentration (Table 5). Mean ERI did not differ between before and after carnitine administration $(0.02 \pm 0.02$ versus $0.02 \pm 0.02, P=0.860)$. Improvement of ERI was found in 10 of 27 patients (37.0\%), and aggravation of ERI in 5 of 27 patients (18.5\%). Changes in BMIPP SS did not correlate with changes in ERI $(r=-0.061, P=0.764)$, and changes in ERI were not associated with decrease in BMIPP SS <-20\% (10\%: Odds ratio, 0.999; 95\% confidence interval, 0.996-1.002; $P=0.449$ ). In a multivariate logistic analysis among the factors of $P<0.1$ in an univariate analysis, decrease in BMIPP SS $<-20 \%$ was associated with baseline serum albumin concentration $(1 \mathrm{~g} / \mathrm{L}$ : odds ratio, 0.669; 95\% confidence interval, 0.456-0.980; $P=0.039)$. In ROC analysis, the cut-off of baseline serum albumin concentration for decrease in BMIPP SS $<-20 \%$ was $35 \mathrm{~g} / \mathrm{L}$ (area under the curve: 0.789). Mean serum albumin concentration one year after administration of L-carnitine tended to be higher than that before L-carnitine administration in patients with changes in BMIPP $\mathrm{SS}<-20 \%(37.9 \pm 1.2$ versus $35.4 \pm 2.8 \mathrm{~g} / \mathrm{L}, P=0.075$, $n=7$ ), but did not differ in patients with changes in BMIPP SS $\pm 20 \%(38.3 \pm 1.8$ versus $39.4 \pm 2.9 \mathrm{~g} / \mathrm{L}$, $P=0.162, n=12)$ or those with changes in BMIPP SS $>20 \%$ (36.4 \pm 3.5 versus $37.9 \pm 3.5 \mathrm{~g} / \mathrm{L}, P=0.142, n=8)$.

\section{Discussion}

The present study showed that chronic intravenous administration of L-carnitine did not significantly affect mean BMIPP SS evaluated by SPECT in hemodialysis patients with LV dysfunction, although circulating levels of L-carnitine increased almost six-fold at 3 month of administration. When we divided the participants of the carnitine group into the three subgroups according to the increase or decrease in BMIPP SS, $25.9 \%$ were allocated to the improved subgroup, whereas $29.6 \%$ were allocated to the deteriorated subgroup. Improved uptake of BMIPP in SPECT after L-carnitine administration was associated with betterment of LVEF. Responders and non-responders may exist among hemodialysis patients regarding the effect of L-carnitine on myocardial fatty acid imaging.

Over $70 \%$ of the energy required by the normal myocardium under aerobic conditions derives from metabolism of FFA. Under hypoxic or ischemic conditions, FFA metabolism is believed to be suppressed and replaced by glucose metabolism, which requires less oxygen consumption. ${ }^{123}$ I-BMIPP is a branched FFA analogue characterized by resistance to $\beta$-oxidation. The metabolism and kinetics of BMIPP in myocardial cells are determined by the following factors: (1) Incorporation from the blood into cardiac muscle cells via the CD36-positive FFA binding protein on the myocardial cell membrane; (2) Back diffusion from myocardial cells into the blood that occurs immediately after incorporation; (3) Intracardiac concentrations of adenosine triphosphate (ATP), which is required for acylation of BMIPP; (4) Accumulation of acyl BMIPP in the lipid pool; and (5) Metabolism 
Table 4 Differences in baseline characteristics among the subgroups of carnitine administration

\begin{tabular}{|c|c|c|c|}
\hline & $\begin{array}{l}\text { BMIPP SS changes }<-20 \% \\
(n=7)\end{array}$ & $\begin{array}{l}\text { BMIPP SS changes between } \pm 20 \% \\
(n=12)\end{array}$ & $\begin{array}{l}\text { BMIPP SS changes }>+20 \% \\
(n=8)\end{array}$ \\
\hline Age, y & $63.9 \pm 11.5$ & $63.3 \pm 11.3$ & $64.8 \pm 12.0$ \\
\hline Male gender, $n(\%)$ & $2(28.6)$ & $7(58.3)$ & $5(62.5)$ \\
\hline Dialysis duration, months & $143.3 \pm 89.1$ & $170.6 \pm 112.7$ & $122.0 \pm 112.6$ \\
\hline Smoking, $n(\%)$ & $1(14.3)$ & $3(25.0)$ & $5(62.5)$ \\
\hline Alcohol, $n(\%)$ & $1(14.3)$ & $3(25.0)$ & $4(50.0)$ \\
\hline Diabetes mellitus, $n(\%)$ & $4(57.1)$ & $6(50.0)$ & $4(50.0)$ \\
\hline Systolic blood pressure before dialysis, $\mathrm{mm} \mathrm{Hg}$ & $135.3 \pm 19.4$ & $134.8 \pm 19.4$ & $134.0 \pm 18.8$ \\
\hline Diastolic blood pressure before dialysis, $\mathrm{mm} \mathrm{Hg}$ & $70.1 \pm 14.1$ & $68.9 \pm 16.1$ & $70.5 \pm 14.7$ \\
\hline Body mass index, $\mathrm{kg} / \mathrm{m}^{2}$ & $21.0 \pm 4.5$ & $24.0 \pm 4.2$ & $22.9 \pm 4.1$ \\
\hline Cardiothoracic ratio, $\%$ & $53.9 \pm 5.7$ & $52.0 \pm 4.5$ & $54.7 \pm 4.7$ \\
\hline Left ventricular ejection fraction, $\%$ & $46.0 \pm 8.8+$ & $52.3 \pm 14.6$ & $60.9 \pm 3.1$ \\
\hline Left ventricular mass index, $\mathrm{g} / \mathrm{m}^{2}$ & $126.0 \pm 35.0$ & $122.4 \pm 25.7$ & $133.5 \pm 11.0$ \\
\hline Mitral early to atrial (E/A) wave velocity ratio & $1.1 \pm 0.6$ & $1.1 \pm 0.7$ & $1.0 \pm 0.4$ \\
\hline Blood hemoglobin, g/L & $104.9 \pm 6.5$ & $109.0 \pm 10.8$ & $103.0 \pm 7.5$ \\
\hline Serum albumin, $g / L$ & $35.4 \pm 2.8^{*}$ & $39.4 \pm 2.9$ & $37.9 \pm 3.5$ \\
\hline Serum calcium, mmol/L & $2.2 \pm 0.2$ & $2.2 \pm 0.1$ & $2.2 \pm 0.2$ \\
\hline Serum inorganic phosphorus, $\mathrm{mmol} / \mathrm{L}$ & $1.6 \pm 0.2$ & $1.5 \pm 0.4$ & $1.6 \pm 0.3$ \\
\hline Serum total cholesterol, $\mathrm{mmol} / \mathrm{L}$ & $3.1 \pm 1.0^{*}$ & $4.4 \pm 0.9$ & $3.8 \pm 0.8$ \\
\hline Serum ferritin, pmol/L & $403.1 \pm 198.2$ & $269.6 \pm 253.0$ & $274.1 \pm 155.7$ \\
\hline Serum intact parathyroid hormone, ng/L & $78.1 \pm 59.9$ & $122.1 \pm 15.9$ & $198.6 \pm 96.9$ \\
\hline Serum C-reactive protein, mg/L & $4.0 \pm 3.7$ & $1.3 \pm 1.1$ & $2.0 \pm 2.6$ \\
\hline Plasma B-type natriuretic peptide, ng/L & $289.2 \pm 245.4$ & $205.6 \pm 229.2$ & $279.5 \pm 234.1$ \\
\hline $\mathrm{HOMA}-\mathrm{IR}, \mathrm{mmol} / \mathrm{L} \cdot \mu \mathrm{U} / \mathrm{ml}$ & $5.8 \pm 2.6$ & $5.4 \pm 2.4$ & $4.6 \pm 2.0$ \\
\hline BMIPP summed score & $15.1 \pm 8.2$ & $22.8 \pm 13.2$ & $16.3 \pm 9.9$ \\
\hline Total carnitine, $\mu \mathrm{mol} / \mathrm{L}$ & $59.3 \pm 52.7$ & $58.9 \pm 41.1$ & $62.3 \pm 59.0$ \\
\hline Free carnitine, $\mu \mathrm{mol} / \mathrm{L}$ & $36.9 \pm 38.6$ & $33.7 \pm 23.3$ & $44.1 \pm 57.1$ \\
\hline Acyl carnitine, $\mu \mathrm{mol} / \mathrm{L}$ & $22.4 \pm 14.4$ & $25.1 \pm 18.0$ & $26.2 \pm 31.3$ \\
\hline Acyl/ free carnitine ratio & $0.72 \pm 0.15$ & $0.73 \pm 0.15$ & $0.64 \pm 0.11$ \\
\hline \multicolumn{4}{|l|}{ Medications } \\
\hline$\alpha_{1}$ blockers, $n(\%)$ & $1(14.3)$ & $0(0)$ & $2(25.0)$ \\
\hline$\beta$ blockers, $n(\%)$ & $5(71.4)$ & $6(50.0)$ & $6(75.0)$ \\
\hline Calcium blockers, $n$ (\%) & $3(42.9)$ & $2(16.7)$ & $2(25.0)$ \\
\hline RAS inhibitors, $n(\%)$ & $3(42.9)$ & $2(16.7)$ & $4(50.0)$ \\
\hline Nitrates, $n(\%)$ & $1(14.3)$ & $2(16.7)$ & $0(0)$ \\
\hline Antiplatelet drugs, $n$ (\%) & $5(71.4)$ & $9(75.0)$ & $4(50.0)$ \\
\hline Anticoagulation drugs, $n(\%)$ & $1(14.3)$ & $1(8.3)$ & $3(37.5)$ \\
\hline Statins, $n(\%)$ & $1(14.3)$ & $4(33.3)$ & $2(25.0)$ \\
\hline
\end{tabular}

SS summed score, HOMA-IR the homeostasis model assessment index of insulin resistance, RAS renin-angiotensin system.

${ }^{*} P<0.05$ versus the subgroup of BMIPP SS changes between $\pm 20 \%$.

$+P<0.05$ versus the subgroup of BMIPP SS changes $>20 \%$.

to $\rho$-iodophenyl acetic acid via $\alpha$ - or $\beta$-oxidation in mitochondria. Of intracoronary-administered BMIPP in canine myocardium, uptake into myocardial cells was $74 \%$, and retention of acyl BMIPP was $65.3 \%$, whereas metabolism via $\alpha$ - or $\beta$-oxidation was only $8.7 \%$. Intracardiac ATP and accumulation in the lipid pool are believed to be significantly associated with early cardiac imaging by BMIPP SPECT (Yamamichi et al. 1995; Tanaka et al. 1997; Kawasaki et al. 1999; Fujibayashi et al. 1990, 1996; Hosokawa et al. 1997).

Experimental administration of etomoxir, a carnitine palmitoyltransferase I inhibitor, to dogs did not affect retention of ${ }^{123} \mathrm{I}$-BMIPP in the heart (Hosokawa et al. 1996). Since only a small fraction of BMIPP is 


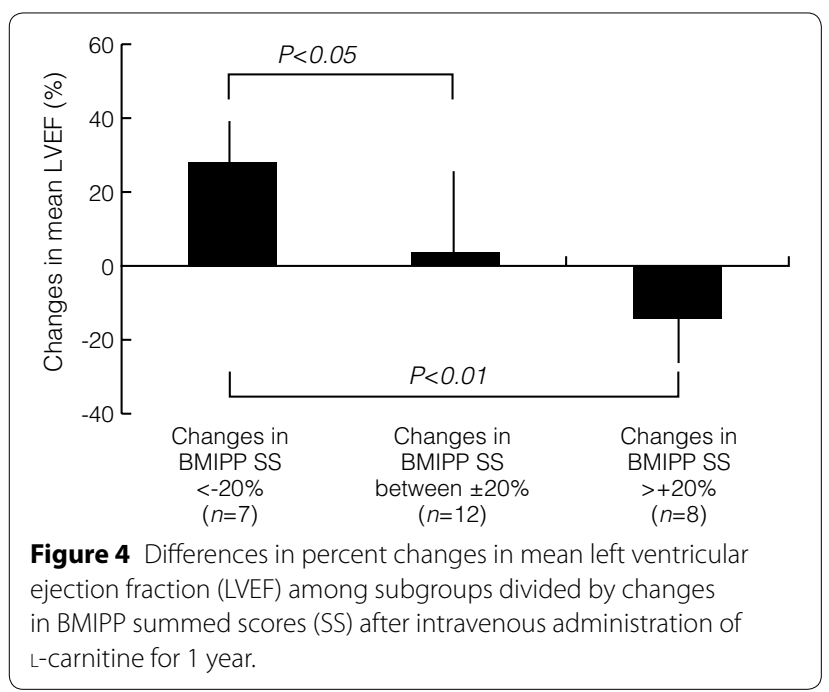

metabolized via $\alpha$ - or $\beta$-oxidation in mitochondria as described above, other mechanisms of L-carnitine besides accelerating BMIPP metabolism would be involved in improving fatty acid imaging in hemodialysis patients. Impaired fatty acid metabolism and consequent accumulation of acyl CoA (Coenzyme A) are characteristic of renal failure (Wanner and Hörl 1988). Accumulated acyl CoAs inhibit glucose uptake by disruption of the intracellular signaling cascade that moves the GLUT4 transporter from its intracellular location to the surface of the myocardial membrane (Dresner et al. 1999; Griffin et al. 1999), and also inhibit enzymes important in glucose metabolism such as pyruvate dehydrogenase (Moore et al. 1992; Sugden et al. 1995): accumulated acyl CoAs thereby enhance insulin resistance. In our previous study, impaired fatty acid metabolism evaluated by BMIPP SPECT was in proportion to HOMA-IR in diabetic and nondiabetic hemodialysis patients (Nishimura et al. 2006). This inhibition of acyl CoAs to glucose metabolism is reportedly suppressed by administration of L-carnitine in hemodialysis patients (Günal et al. 1999). $\mathrm{L}$-Carnitine reduces the concentration of acyl CoA esters and improves efflux of excess acyl carnitine from the mitochondria and myocardium via an exchange transport system (Kobayashi and Fujiwara 1994). By reducing acyl CoAs from the mitochondria, L-carnitine may enhance glucose oxidation and increase myocardial synthesis of ATP in spite of impaired fatty acid metabolism.

In this study, baseline serum albumin concentration below $35 \mathrm{~g} / \mathrm{L}$ was the potent predictor for improvement in BMIPP SPECT by administration of L-carnitine.
Table 5 Univariate logistic analysis for BMIPP SS changes $<-20 \%$

\begin{tabular}{|c|c|c|c|}
\hline & Odds ratio & $95 \% \mathrm{Cl}$ & $P$ \\
\hline Age (1 y) & 0.991 & $0.921-1.067$ & 0.811 \\
\hline Male gender & 0.267 & $0.041-1.727$ & 0.166 \\
\hline Dialysis duration (1 month) & 0.999 & $0.991-1.008$ & 0.862 \\
\hline Smoking & 0.250 & $0.025-2.489$ & 0.237 \\
\hline Alcohol & 0.310 & $0.031-3.111$ & 0.319 \\
\hline Diabetes mellitus & 1.333 & $0.235-7.556$ & 0.745 \\
\hline $\begin{array}{l}\text { Systolic blood pressure before } \\
\text { dialysis }(1 \mathrm{~mm} \mathrm{Hg})\end{array}$ & 1.005 & $0.959-1.053$ & 0.826 \\
\hline $\begin{array}{l}\text { Diastolic blood pressure before } \\
\text { dialysis }(1 \mathrm{~mm} \mathrm{Hg})\end{array}$ & 0.998 & $0.940-1.059$ & 0.942 \\
\hline Body mass index $\left(1 \mathrm{~kg} / \mathrm{m}^{2}\right)$ & 0.824 & $0.629-1.079$ & 0.159 \\
\hline Cardiothoracic ratio (1\%) & 1.036 & $0.864-1.243$ & 0.700 \\
\hline $\begin{array}{l}\text { Left ventricular ejection fraction } \\
\qquad(1 \%)\end{array}$ & 0.935 & $0.867-1.008$ & 0.081 \\
\hline $\begin{array}{l}\text { Left ventricular mass index, }(1 \mathrm{~g} / \\
\left.\mathrm{m}^{2}\right)\end{array}$ & 0.999 & $0.964-1.034$ & 0.938 \\
\hline $\begin{array}{l}\text { Mitral early to atrial (E/A) wave } \\
\text { velocity ratio (1) }\end{array}$ & 1.289 & $0.310-5.354$ & 0.727 \\
\hline Blood hemoglobin (1 g/L) & 0.801 & $0.302-2.121$ & 0.655 \\
\hline Serum albumin (1 g/L) & 0.669 & $0.456-0.980$ & 0.039 \\
\hline Serum calcium (1 mmol/L) & 0.895 & $0.002-437.4$ & 0.972 \\
\hline $\begin{array}{l}\text { Serum inorganic phosphorus (1 } \\
\mathrm{mmol} / \mathrm{L})\end{array}$ & 1.863 & $0.096-36.204$ & 0.681 \\
\hline $\begin{array}{l}\text { Serum total cholesterol } \\
(1 \mathrm{mmol} / \mathrm{L})\end{array}$ & 0.244 & $0.062-0.963$ & 0.044 \\
\hline Serum ferritin (1 pmol/L) & 1.004 & $0.999-1.009$ & 0.097 \\
\hline $\begin{array}{l}\text { Serum intact parathyroid hormone } \\
(1 \mathrm{ng} / \mathrm{L})\end{array}$ & 0.991 & $0.981-1.002$ & 0.120 \\
\hline Serum C-reactive protein (1 mg/L) & 1.421 & $1.004-2.010$ & 0.047 \\
\hline $\begin{array}{l}\text { Plasma B-type natriuretic peptide } \\
\text { (1 ng/L) }\end{array}$ & 1.001 & $0.997-1,005$ & 0.587 \\
\hline $\mathrm{HOMA-IR} \mathrm{(1} \mathrm{mmol/L \bullet \mu U/ml)}$ & 1.171 & $0.790-1.738$ & 0.432 \\
\hline Serum total carnitine $(1 \mu \mathrm{mol} / \mathrm{L})$ & 0.999 & $0.983-1.014$ & 0.870 \\
\hline Serum free carnitine $(1 \mu \mathrm{mol} / \mathrm{L})$ & 0.999 & $0.976-1.023$ & 0.952 \\
\hline Serum acyl carnitine $(1 \mu \mathrm{mol} / \mathrm{L})$ & 0.992 & $0.946-1.040$ & 0.732 \\
\hline Acyl/free carnitine ratio (1) & 3.937 & $0.006-2774.282$ & 0.682 \\
\hline BMIPP summed score (1) & 0.952 & $0.866-1.047$ & 0.311 \\
\hline \multicolumn{4}{|l|}{ Medications } \\
\hline$\alpha_{1}$ blockers & 1.500 & $0.115-19.640$ & 0.757 \\
\hline$\beta$ blockers & 1.667 & $0.257-10.792$ & 0.592 \\
\hline Calcium blockers & 3.000 & $0.469-19.176$ & 0.246 \\
\hline RAS inhibitors & 1.750 & $0.296-10.340$ & 0.537 \\
\hline Nitrates & 1.500 & $0.115-19.640$ & 0.757 \\
\hline Antiplatelet drugs & 1.346 & $0.205-8.819$ & 0.757 \\
\hline Anticoagulation drugs & 0.667 & $0.061-7.230$ & 0.739 \\
\hline Statins & 0.389 & $0.038-3.970$ & 0.426 \\
\hline
\end{tabular}

SS summed score, $\mathrm{Cl}$ confidence interval, HOMA-IR the homeostasis model, RAS renin-angiotensin system. 
Serum albumin concentration basically correlates with body protein stores, and serum albumin concentration below $38 \mathrm{~g} / \mathrm{L}$ suggests a diagnosis of protein-energy wasting (Fouque et al. 2011), which is defined as a pathological state in which there is a continuous decrease or wasting of both protein deposits and energy reserves. Impaired protein anabolism, as well as insulin resistance, is one of the metabolic alterations in patients with end-stage kidney disease (Avesani et al. 2011). In animal studies, L-carnitine administration directly suppressed branched-chain alpha-keto acid dehydrogenase activity; this would lead to increase in intracellular levels of branched-chain amino acids (Owen et al. 2001). Branched-chain amino acids like leucine, valine, and isoleucine play an important role in regulation of body protein turnover (Nakashima et al. 2005; Kimball and Jefferson 2006). Biolo et al. (2008) reported that L-carnitine supplementation was associated with lower rates of leucine oxidation and appearance from proteolysis during the insulin clamp studies than after placebo supplementation. In the present study, mean serum albumin concentration in the subgroup of changes in BMIPP SS $<-20 \%$ was higher after L-carnitine administration than before, whereas it did not differ between before and after L-carnitine administration in other subgroups. The results of this study indicate that the state of protein-energy wasting may be involved in the mechanism of impaired myocardial fatty acid imaging and that protein-sparing effects of $\mathrm{L}$-carnitine is likely to play a role in improving impaired BMIPP SPECT in this population. Further investigation is needed to clarify this important point.

This study has several limitations. We used CAG to confirm the presence of suspected myocardial ischemia in the participants. "Without significant obstructive CAD" does not necessarily mean that the epicardial coronary arteries are normal. Since histopathological and intravascular ultrasound studies have demonstrated the propensity of angiography to underestimate lesional severity (Porter et al. 1993), we cannot exclude the possibility that some angiographically non-significant lesions were flow-limiting. During the follow-up of 72 participants, 11 participants were lost for follow-up, and 8 participants were discontinued from this study; this high rate of exclusion of participants from the analysis would be a potential source of bias in this study. Since our study was a small, non-blinded, open-labeled trial, it would be difficult to capture a significant effect of L-carnitine and to precisely perform a multivariate analysis. A large, randomized trial is needed to clarify the effects of $\mathrm{L}$-carnitine on impaired myocardial fatty acid imaging.

In conclusion, long-term intravenous administration of L-carnitine did not improve myocardial fatty acid imaging evaluated by BMIPP SPECT in all hemodialysis patients with LV dysfunction. However, improvement in BMIPP SPECT was found in almost one-forth of the participants. Hypoalbuminemia below $35 \mathrm{~g} / \mathrm{L}$ could be one of the clinical parameters to select hemodialysis patients for administration of L-carnitine to improve fatty acid metabolism and cardiac dysfunction. Intravenous L-carnitine might be an alternative way to treat uremic cardiomyopathy in addition to conventional therapies in a selected group of hemodialysis patients.

\section{Abbreviations}

ATP: adenosine triphosphate; BMIPP: $\beta$-methyliodophenyl pentadecanoic acid; BNP: B-type natriuretic peptide; CoA: coenzyme A; CAD: coronary artery disease; CAG: coronary angiography; CRP: C-reactive protein; E/A: early to atrial; ESA: erythropoiesis stimulating agent; ERI: erythropoiesis stimulating agent resistance index; FFA: free fatty acids; $\mathrm{Hb}$ : hemoglobin; HOMA-IR: homeostasis model assessment index of insulin resistance; LV: left ventricular; LVEF: left ventricular ejection fraction; LVMI: left ventricular mass index; ROC: receiver-operating characteristic; SPECT: single-photon emission computed tomography; SS: summed scores.

\section{Authors' contributions}

MN (corresponding author) participated in the design and coordination of this study, performed data analysis, and was involved in the writing of the manuscript. TT and TT participated in the interpretation of the SPECT. NS, MN, $\mathrm{TH}$, and SY contributed to the design and analysis of data. HK and TO were involved in the writing of the manuscript. All authors read and approved the final manuscript.

\section{Author details}

${ }^{1}$ Cardiovascular Division, Toujinkai Hospital, 83-1, Iga, Momoyama-cho, Fushimi-ku, Kyoto 612-8026, Japan. ${ }^{2}$ Department of Nephrology, Toujinkai Hospital, Kyoto, Japan. ${ }^{3}$ Department of Urology, Toujinkai Hospital, Kyoto, Japan. ${ }^{4}$ Department of Urology, Toujinkai Clinic, Kyoto, Japan.

\section{Acknowledgements}

The authors thank Mr. Toshio Furuta and Mr Keigo Takaichi for the collection of the clinical data, Ms Maki Kitahara for echocardiography, and Mr Toshiyuki Takenaka for performance of BMIPP SPECT in Toujinkai Hospital. We also thank the staff of Interventional Cardiology at Kyoto Second Red Cross Hospital for coronary angiography and cardiac disease assessment.

\section{Compliance with ethical guidelines}

\section{Competing interests}

The authors declare that they have no competing interests.

Received: 2 April 2015 Accepted: 26 June 2015

Published online: 16 July 2015

\section{References}

Avesani CM, Kamimura MA, Cuppani L (2011) Energy expenditure in chronic kidney disease patients. J Ren Nutr 21:27-30

Biolo G, Stulle M, Bianco F, Mengozzi G, Barazzoni R, Vasile A et al (2008) Insulin action on glucose and protein metabolism during L-carnitine supplementation in maintenance haemodialysis patients. Nephrol Dial Transplant 23:991-997

Dresner A, Laurent D, Marcucci M, Griffin ME, Dufour S, Cline GW et al (1999) Effects of free fatty acids on glucose transport and IRS-1 associated phosphatidylinositol 3-kinase activity. J Clin Invest 103:253-259

Fouque D, Pelletier S, Mafra D, Chauveau P (2011) Nutrition and chronic kidney disease. Kidney Int 80:348-357

Fujibayashi Y, Yonekura Y, Takemura Y, Wada K, Matsumoto K, Tamaki N et al (1990) Myocardial accumulation of iodinated beta-methyl-branched 
fatty acid analogue, iodine-125-15-(p-iodophenyl)-3-( R, S)methyl pentadecanoic acid (BMIPP), in relation to ATP concentration. J Nucl Med 31:1818-1822

Fujibayashi Y, Nohara R, Hosokawa R, Okuda K, Yonekura Y, Tamaki N et al (1996) Metabolism and kinetics of iodine-123-BMIPP in canine myocardium. J Nucl Med 37:757-761

Griffin ME, Marcucci MJ, Cline GW, Bell K, Barucci N, Lee D et al (1999) Free fatty acid-induced insulin resistance is associated with activation of protein kinase $C$ theta and alterations in the insulin signaling cascade. Diabetes 48:1270-1274

Günal Al, Celiker H, Dönder E, Günal SY (1999) The effects of L-carnitine on insulin resistance in hemodialysis patients with chronic renal failure. J Nephrol 12:38-40

Hosokawa R, Nohara R, Fujibayashi Y, Okuda K, Ogino M, Hata T et al (1996) Metabolic fate of iodine-123-BMIPP in canine myocardium after administration of etomoxir. J Nucl Med 37:1836-1840

Hosokawa R, Nohara R, Fujibayashi Y, Okuda K, Ogino M, Hata T et al (1997) Myocardial kinetics of iodine-123-BMIPP in canine myocardium after regional ischemia and reperfusion: Implications for clinical SPECT. J NuCl Med 38:1857-1863

Kawasaki T, Ito K, Okano A, Nagata K, Okamoto A, Yoneyama S et al (1999) A dynamic change by 1231-15-(p-iodophenyl)-3-R, S-methyl pentadecanoic acid myocardial single photon emission computed tomography in a 55-year-old woman. Jpn Circ J 63:732-736

Kimball SR, Jefferson LS (2006) Signaling pathways and molecular mechanisms through which branched-chain amino acids mediate translational control of protein synthesis. J Nutr 136:227S-231S

Kobayashi A, Fujiwara S (1994) Effect of L-carnitine on mitochondrial acyl CoA esters in the ischemic dog heart. J Moll Cell Cardiol 26:499-508

Matsumoto Y, Sato M, Ohashi H, Araki H, Tadokoro M, Osumi Y et al (2000) Effects of L-carnitine supplementation on cardiac morbidity in hemodialysis patients. Am J Nephrol 20:201-207

Moore KH, Dandurand DM, Kiechle FL (1992) Fasting induced alterations in mitochondrial palmitoyl-CoA metabolism may inhibit adipocyte pyruvate dehydrogenase acitivity. Int J Biochem 24:809-814

Moroi M, Tamaki Nishimura M, Haze K, Nishimura T, Kusano E, Akiba T et al (2013) Association between abnormal myocardial fatty acid metabolism and cardiac-derived death among patients undergoing hemodialysis: Results from a cohort study in Japan. Am J Kidney Dis 61:466-475

Nakashima K, Ishida A, Yamazaki M, Abe H (2005) Leucine suppresses myofibrillar proteolysis by down-regulating ubiquitin-proteasome pathway in chick skeletal muscles. Biochem Biophys Res Commun 336:660-666

Nishimura M, Murase M, Hashimoto T, Kobayashi H, Yamazaki S, Imai R et al (2006) Insulin resistance and impaired myocardial fatty acid metabolism in dialysis patients with normal coronary arteries. Kidney Int 69:553-559

Nishimura M, Tsukamoto K, Hasebe N, Tamaki N, Kikuchi K, Ono T (2008a) Prediction of cardiac death in hemodialysis patients by myocardial fatty acid imaging. J Am Coll Cardiol 51:139-145

Nishimura M, Tokoro T, Nishida M, Hashimoto T, Kobayashi H, Yamazaki S et al (2008b) Myocardial fatty acid imaging identifies a group of hemodialysis patients at high risk for cardiac death after coronary revascularization. Kidney Int 74:513-520
Nishimura M, Tsukamoto K, Tamaki N, Kikuchi K, Iwamoto N, Ono T (2011) Risk stratification for cardiac death of hemodialysis patients without obstructive coronary artery disease. Kidney Int 79:363-371

Nishimura M, Okamoto Yu, Tokoro T, Sato N, Nishida M, Hashimoto T et al (2014) Clinical potential of oral nicorandil to improve myocardial fatty acid metabolism after percutaneous coronary intervention in hemodialysis patients. Nephron Clin Pract 126:24-32

Nishimura M, Okamoto Yu, Takatani T, Sato N, Nishida M, Hashimoto T et al (2015) Improvement of myocardial fatty acid metabolism by oral nicorandil in hemodialysis patients without coronary artery disease. J Nephrol 28:227-234

Owen KQ, Jit H, Maxwell CV, Goodband RD, Tokach MD, Tremblay GC et al (2001) Dietary L-carnitine suppresses mitochondrial branched-chain keto acid dehydrogenase activity and enhances protein accretion and carcass characteristics of swine. J Anim Sci 79:3104-3112

Porter TR, Sears T, Xie F, Michels A, Mata J, Welsh D et al (1993) Intravascular ultrasound study of angiographically mildly diseased coronary arteries. J Am Coll Cardiol 22:1858-1865

Romagnoli GF, Nasco A, Carraro G, Lidestri V (2002) Beneficial effects of L-carnitine in dialysis patients with impaired left ventricular function: an observational study. Curr Med Res Opin 18:172-175

Sahn DJ, DeMaria A, Kisso J, Weyman A (1978) Recommendations regarding quantitation in M-mode echocardiography: results of a survey of echocardiographic measurements. Circulation 58:1072-1083

Sakurabayashi T, Takaesu Y, Haginoshita S, Takeda T, Aoike I, Miyazaki S et al (1999) Improvement of myocardial fatty acid metabolism through L-carnitine administration to chronic hemodialysis patients. Am J Nephrol 19:480-484

Sugden MC, Orfali KA, Holness MJ (1995) The pyruvate dehydrogenase complex: nutrient control and the pathogenesis of insulin resistance. J Nutr 125(6 Suppl):1746S-1752S

Suzuki Y, Narita M, Yamazaki H (1982) Effects of L-carnitine on arrhythmias during hemodialysis. Jpn Heart J 23:349-359

Takahashi M, Ueda S, Misaki H, Sugiyama N, Matsumoto K, Matsuo N et al (1994) Carnitine determination by an enzymatic cycling method with carnitine dehydrogenase. Clin Chem 40:817-821

Tanaka T, Okamoto F, Sohmiya K, Kawamura K (1997) Lack of myocardial iodine-123 15-(p-iodiphenyl)-3-R, S-methyl pentadecanoic acid (BMIPP) uptake and CD36 abnormality. Jpn Circ J 61:724-725

Van Es A, Henny FC, Kooistra MP, Lobatto S, Scholte HR (1992) Amelioration of cardiac function by L-carnitine administration in patients on haemodialysis. Contrib Nephrol 98:28-35

Wanner C, Hörl WH (1988) Carnitine abnormalities in patients with renal insufficiency. Pathophysiological and therapeutical aspects. Nephron 50:89-102

Yamamichi Y, Kusuoka H, Morishita K, Shirakami Y, Kurami M, Okano K et al (1995) Metabolism of iodine-123-BMIPP in perfused rat hearts. J Nucl Med 36:1043-1050

\section{Submit your manuscript to a SpringerOpen ${ }^{\circ}$ journal and benefit from:}

- Convenient online submission

- Rigorous peer review

- Immediate publication on acceptance

- Open access: articles freely available online

- High visibility within the field

- Retaining the copyright to your article

Submit your next manuscript at springeropen.com 